These trends should be considered while designing and conducting future trials. Attention to site training and data quality may be particularly important to control high placebo rates, especially as trial sizes decrease.

Disclosure of Interests: Ewa Olech Grant/research support from: BMS, Consultant of: Abbvie, Amgen, Remegen, Employee of: IQVIA, Speakers bureau: Abbvie, Amgen, Merck, Pfizer, UCB, Eduard van Rijen Employee of: IQVIA, Faizi Hussain Employee of: IQVIA, Gregory Dennis Employee of: IQVIA, Ali Ashrafzadeh Employee of: IQVIA, Joan T Merrill Grant/research support from: Xencor, Bristol Myers Squibb, Glaxo Smith Kline, Consultant of: Xencor, Abbvie, UCB, Glaxo Smith Kline, EMD Serono, Astellas, Remegen, Celgene/Bristol Myers Squibb, Exagen, Astra Zeneca, Amgen, Jannsen, Servier, ILTOO, Daitchi Sankyo, Lilly, Paid instructor for: Abbvie, Bristol Myers Squibb

DOI: 10.1136/annrheumdis-2020-eular.3414

\section{SAT0190 CORTICOSTEROID AND OPIOID USE REMAIN HIGH IN SYSTEMIC LUPUS ERYTHEMATOSUS (SLE) PATIENTS RECEIVING BIOLOGIC THERAPY: A RETROSPECTIVE CLAIMS DATABASE ANALYSIS}

J. Birt ${ }^{1}$, J. Wu ${ }^{1}$, K. Griffing ${ }^{1}$, N. Bello Vega ${ }^{1}$, N. Princic ${ }^{2}$, I. Winer ${ }^{2}$, C. Lew ${ }^{2}$, K. Costenbader ${ }^{3} .{ }^{1}$ Eli Lilly and Company, Indianapolis, United States of America; ${ }^{2}$ IBM Watson Health, Cambridge, United States of America; ${ }^{3}$ Brigham and Women's Hospital and Harvard Medical School, Boston, United States of America

Background: SLE is managed by variable combinations of five drug classes: antimalarials, biologics, corticosteroids, non-steroidal anti-inflammatory agents, and immunosuppressants. Opioids are commonly prescribed to SLE patients despite not being effective for the management of long-term musculoskeletal pain. ${ }^{1}$

Objectives: To describe corticosteroid and opioid use among SLE patients in the United States, and the impact of belimumab initiation on prescribing patterns.

Methods: This retrospective study used MarketScan administrative claims databases to select insured adults, age $\geq 18$, with a diagnosis (ICD-9/10 710.0 \& M32) of SLE between 1/1/2012 and 5/31/2018 (earliest SLE diagnosis = index date). Patients were followed from index through the earliest of health plan disenrollment or 5/31/2019 (minimum of 12 months). Corticosteroid use was measured in the 12 months following SLE index date. Average daily dose of oral corticosteroids in prednisone equivalents was measured for 12 months after corticosteroid initiation. Opioid use was measured overall, and by strength and length of treatment (chronic use defined as $>90$ days of supply). Oral corticosteroid and opioid use were compared in the 6 months before and after initiation of belimumab.

Results: Of 49,413 SLE patients eligible for analysis, mean [SD] age was 50.1 [14.0] years, 90.2\% were female, and average follow-up was 3.6 [1.9] years. 89.8\% of patients received any SLE treatment and $68.5 \%$ received corticosteroids. The average number of corticosteroid prescriptions was 4.6 [4.1] during 12 months of follow-up. $52.6 \%$ of patients had $\geq 1$ claim for an opioid prescription in the 12 months after SLE index and $34.6 \%$ were identified as having chronic opioid treatment. Among patients with oral corticosteroid treatment and 12 months of study enrollment post-corticosteroid initiation, the average daily dose for oral corticosteroids was 19.4 [14.2] mg and $59.6 \%$ had a high average daily dose of $>15 \mathrm{mg}$ (Figure 1). Among 1,710 patients with belimumab treatment and 6 months of study enrollment after the first prescription, use of oral corticosteroids decreased by $9.1 \%(p=0.001)$, average daily dose decreased from 14.5 [18.4] mg to 11.9 [18.0] $\mathrm{mg}(\mathrm{p}<0.001)$ in the 6 months post initiation as compared to the 6 months prior. However, $48.6 \%$ of patients remained on a medium $(7.5 \mathrm{mg}-<15 \mathrm{mg})$ or high dose $(\geq 15 \mathrm{mg})$. Initiation of belimumab resulted in no change in opioid use (Table 1).

Table 1.

\begin{tabular}{|c|c|c|c|c|c|}
\hline & \multicolumn{2}{|c|}{$\begin{array}{c}\text { Before } \\
\text { Belimumab }\end{array}$} & \multicolumn{2}{|c|}{$\begin{array}{c}\text { After } \\
\text { Belimumab }\end{array}$} & \multirow{2}{*}{$\begin{array}{c}\begin{array}{c}\text { p-value, } \\
\text { pre vs. }\end{array} \\
\text { post } \\
\text { Belimumab }\end{array}$} \\
\hline & $(\mathrm{N}=$ & $1,710)$ & $(\mathrm{N}=$ & $1,710)$ & \\
\hline $\begin{array}{l}\text { Patients with an oral steroid prescription } \\
(\mathrm{N}, \%)\end{array}$ & 1,242 & $72.6 \%$ & 1,086 & $63.5 \%$ & 0.001 \\
\hline Number of prescriptions (Mean, SD) & 2.3 & 2.3 & 2.1 & 2.3 & $<0.001$ \\
\hline Average daily dose (Mean, SD) & 14.5 & 18.4 & 11.9 & 18.0 & $<0.001$ \\
\hline Low average daily dose ( $>0$ to $<7.5 \mathrm{mg}$ ) $(\mathrm{N}, \%)$ & 210 & $12.3 \%$ & 255 & $14.9 \%$ & 0.037 \\
\hline $\begin{array}{l}\text { Medium average daily dose }(7.5-<15 \mathrm{mg}) \\
(\mathrm{N}, \%)\end{array}$ & 389 & $22.7 \%$ & 334 & $19.5 \%$ & 0.041 \\
\hline $\begin{array}{l}\text { High average daily dose (15 } \mathrm{mg} \text { or more) } \\
(\mathrm{N}, \%)\end{array}$ & 643 & $37.6 \%$ & 497 & $29.1 \%$ & $<0.001$ \\
\hline Patients with an opioid prescription (N, \%) & 901 & $52.7 \%$ & 861 & $50.4 \%$ & 0.341 \\
\hline Weak opioids & 356 & $20.8 \%$ & 312 & $18.2 \%$ & 0.089 \\
\hline Strong opioids & 699 & $40.9 \%$ & 695 & $40.6 \%$ & 0.915 \\
\hline Acute Opioid Use & 538 & $59.7 \%$ & 486 & $56.4 \%$ & 0.165 \\
\hline Chronic opioid use & 363 & $40.3 \%$ & 375 & $43.6 \%$ & 0.165 \\
\hline
\end{tabular}

Conclusion: These results suggest that a strikingly high proportion of patients with SLE are treated with corticosteroids to control the disease and opioid therapy to manage chronic pain. While there was no change in opioid use, corticosteroid use decreased following initiation of belimumab.

\section{References:}

[1] Chen SK, Feldman CH, Brill G, et al. Use of prescription opioids among patients with rheumatic diseases compared to patients with hypertension in the USA: a retrospective cohort study. BMJ 2019;9:e027495

Disclosure of Interests: : Julie Birt Shareholder of: Eli Lilly and Company, Employee of: Eli Lilly and Company, Jianmin Wu Shareholder of: Eli Lilly and Company, Employee of: Eli Lilly and Company, Kirstin Griffing Shareholder of: Eli Lilly and Company, Employee of: Eli Lilly and Company, Natalia Bello Vega Shareholder of: Eli Lilly and Company, Employee of: Eli Lilly and Company, Nicole Princic Employee of: I work for IBM Watson Health who was paid by Eli Lilly who funded this research., Isabelle Winer Employee of: I work for IBM Watson Health who was paid by Eli Lilly who funded this research., Carolyn Lew Employee of: I work for IBM Watson Health who was paid by Eli Lilly who funded this research., Karen Costenbader Grant/research support from: Merck, Consultant of: Astra-Zeneca

Figure 1: Steroid Dosing During the 12 Months Following Initiation of Oral Steroids

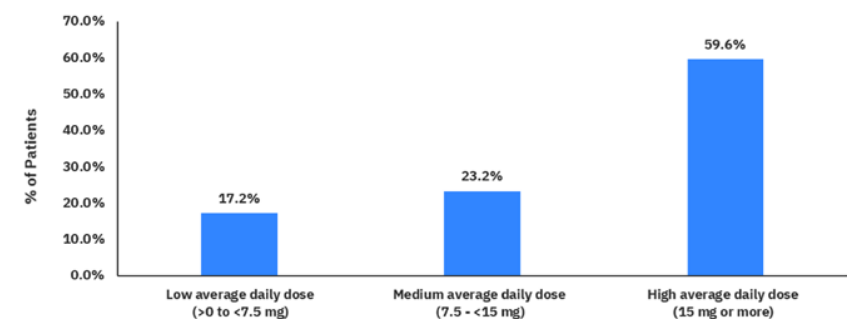

DOI: 10.1136/annrheumdis-2020-eular.1326

\begin{tabular}{|l} 
SAT0191 \\
PLASMA PROTEOMICS IDENTIFIES A PROTEIN \\
SIGNATURE ASSOCIATED WITH RESPONSE TO \\
RITUXIMAB IN PATIENTS WITH SLE
\end{tabular}

J. Reynolds ${ }^{1,2}$, J. Prattley ${ }^{3}$, M. Lunt ${ }^{3}$, I. N. Bruce ${ }^{3,4} .{ }^{1}$ University of Birmingham, Institute of Inflammation and Ageing, Birmingham, United Kingdom; ${ }^{2}$ Sandwell and West Birmingham Hospitals NHS Trust, Rheumatology Department, Birmingham, United Kingdom; ${ }^{3}$ University of Manchester, Division of Musculoskeletal and Dermatological Sciences, Manchester, United Kingdom ${ }^{4}$ Manchester University NHS Foundation Trust, NIHR Manchester Biomedical Research Centre, Manchester, United Kingdom

Background: Rituximab (RTX) is B cell-depleting biological therapy used in the treatment of systemic lupus erythematosus (SLE). Response rates are typically around $50 \%$ and there are currently no robust biomarkers to identify which patients are more likely to respond.

Objectives: To determine whether proteomic analysis of baseline plasma samples could identify novel biomarkers of response to RTX in patients with active SLE. Methods: Patients with SLE ( $\geq 4$ ACR criteria) receiving RTX for active disease (BILAG A or 2 BILAG B scores) from the UK-based BILAG-BR register were included. Improvement at 12 months was defined as a reduction to $\leq 1$ BILAG $B$ score with no increase in either SLEDAI score or steroid dose. Proteomic analysis was performed on baseline plasma samples using sequential window acquisition of all theoretical fragment ion spectra mass spectrometry (SWATH-MS). Data were aligned and normalised to give relative protein abundance. A Lasso penalised logistic regression, with an outcome of improvement at 12 months, was used to perform the variable selection procedure using the R package 'glmnet'. The penalty metric was set at the value which minimised deviance in a 10-fold cross-validation procedure. Confounding variables of sex, age, ethnicity, oral steroid dose, and SLEDAI score had no penalty applied and were thus forcibly retained in the model. Protein-protein interaction networks were visualised using STRING v11.0.

Results: 70 patients of whom $63 / 70(90 \%)$ were female with a median (IQR) age of $41(32,51)$ years and disease duration of $11(6,20)$ years at baseline were included. Patients had active disease with a median SLEDAI score of $10(6,16)$. All patients received RTX according to NHS England guidelines. Of 829 proteins, 815 were detected in at least 1 patient. We identified 9 proteins which were associated with clinical improvement at 12 months. A literature search identified that these proteins have relevance to $T$ cell function, complement activation and lupus nephritis. Gender had the greatest weight in the model followed by Serpin Family A Member 10 (SERPINA10) and complement factor B (CFB). Protein interaction networks linked SERPINA10 to CFB by C3 complement (figure). 